\title{
Determination of the Plasmodium vivax relapse pattern in Camopi, French Guiana

\author{
Matthieu Hanf ${ }^{1}$, Aurélia Stéphani², Célia Basurko ${ }^{1}$, Mathieu Nacher ${ }^{1}$ and \\ Bernard Carme*1,2
}

Address: ${ }^{1}$ Centre d'Investigation Clinique - Epidémiologie Clinique Antilles Guyane CIC-EC Inserm 802, Centre Hospitalier de Cayenne, Guyane Française and ${ }^{2}$ Laboratoire Hospitalo-Universitaire de Parasitologie et Mycologie Médicale, Equipe EA3593, UFR Médecine - Université des Antilles et de la Guyane, Cayenne, Guyane Française

Email: Matthieu Hanf - matthieu.hanf@ch-cayenne.fr; Aurélia Stéphani - aurelia.stefani@gmail.com; Célia Basurko - c.basurko@free.fr; Mathieu Nacher - m_nacher@lycos.com; Bernard Carme* - carme.bernard@wanadoo.fr

* Corresponding author

Published: 4 December 2009

Malaria Journal 2009, 8:278 doi:10.1 I86/I475-2875-8-278

This article is available from: http://www.malariajournal.com/content/8/I/278

(C) 2009 Hanf et al; licensee BioMed Central Ltd.

This is an Open Access article distributed under the terms of the Creative Commons Attribution License (http://creativecommons.org/licenses/by/2.0), which permits unrestricted use, distribution, and reproduction in any medium, provided the original work is properly cited.

\begin{abstract}
Background: Malaria is a major public health problem in French Guiana, where Plasmodium vivax has become the dominant malaria species since 2000. As in others endemic areas, it is important to specify the pattern of vivax malaria relapses and to try to discriminate efficiently re-infections from relapses.
\end{abstract}

Methods: This study was conducted in children born between January I, 200I and December 3I, 2008 in Camopi, an Amerindian village located in the Amazon forest $(n=325)$, using an open cohort design. Primary and secondary attack rates of $P$. vivax were calculated using survival analysis. With the difference between the primary and secondary rates, this study aimed to estimate indirectly $P$. vivax relapse rate and evaluate its time evolution.

Results: Of the 1042 malaria attacks recorded, $689(66 \%)$ were due to $P$. vivax (without mixed infection). One hundred and fifty one children had their primary attack with $P$. vivax and 106 had their two first attacks with $P$. vivax. In the absence of primaquine treatment, it was shown that $P$. vivax relapses mainly occurred during the first three months after the first attack. Thirty percent of children never had a relapse, $42 \%$ had a relapse before the first month after primary attack, $59 \%$ before the second month and $63 \%$ before the third month.

Conclusion: This study confirmed that the relapse pattern in Camopi was compatible with the pattern described for the $P$. vivax Chesson (tropical) strain. In addition, due to the relapse rate time evolution, a simple arbitrary classification rule could be constructed: before 90 days after the primary attack, the secondary attack is a relapse; after 90 days, it is a re-infection. Adapted management of malaria cases based on these results could be devised.

\section{Background}

Traditionally, Plasmodium vivax was considered as a relatively benign malaria parasite, which could be easily treated. For the past 10 years, this has been questioned [1]. It has been shown that malaria could be involved in severe disease [2]. Furthermore, P. vivax has recently re- 
emerged [3] and drug resistances, mainly chloroquinoresistance have developed in several areas[4]. Primaquine treatment, the only therapeutic option against relapse, might also be failing [5]. It requires a 14-day course and G6PD deficiency screening, which is difficult and costly in some areas.

In French Guiana, $P$. vivax has become the dominant malaria species since 2000, with more than $60 \%$ of malaria attacks [6]. Knowledge about its relapse pattern is limited. Plasmodium falciparum remains predominant on the Maroni River, where the maroon populations are mostly Duffy negative and, therefore, resistant to $P$. vivax. Plasmodium malariae has been observed in $2 \%$ of malaria cases.

Differentiation of re-infection from relapse is very difficult; most articles use a combined risk or rate of re-infection and relapse $[7,8]$, or estimated the relapse risk based on the frequency of $P$. vivax during the non-transmission season $[9,10]$. Although molecular epidemiology introduced new methods to discriminate re-infection from relapse, these methods are very expensive and, in many cases, they could not address the question accurately [1113]. In French Guiana, there is a widespread belief that $P$. vivax was of the 'tropical' type, which is characterized by an early primary attack, followed by a short latent period before appearance of frequent relapses during the next year, but no published evidence from French Guiana or elsewhere in South America supports this belief.

The study objectives were to determine the relapse pattern of $P$. vivax using an alternative method and to propose a simple classification to easily differentiate re-infections from relapses.

\section{Methods}

This research was carried out in Camopi, an Amerindian village (Wayampi and Emerillon) located in the Amazon forest along the Oyapock River, which marks the eastern border with Brazil. The incidence of malaria there is around $40 \%$ [14]. A retrospective study using an open cohort design was carried out with all Camopi children born between January 1, 2001 and December 31, 2008.

The children came to the health center approximately once a month, generally at the time of illness or for systematic visits (i.e. vaccination). Every six months, there is a verification that all newborn children are included in the cohort, that all children are present in the village, and that all the malaria data is collected. Data for children for whom follow-up by the health center had been interrupted was right censored at the interruption date. It was assumed that all malaria attacks were recorded at the local health centre [15]. The Camopi health center ensures free early diagnosis and treatment of malaria cases. Because of the extreme isolation, no other health facilities (public or private) are available in this part of the Amazonian forest.

The list of all clinical malaria episodes, their date of occurrence, Plasmodium species identification were made in the Camopi health center by two physicians, two nurses, and one Amerindian assistant. All thin blood smears were first analysed in Camopi by a trained nurse and then checked by the parasitological unit of Cayenne General Hospital, the referent malaria center in French Guiana.

Malaria was defined as temperature $>38^{\circ} \mathrm{C}$ at the time of consultation or fever within the past 48 hours associated with Plasmodium asexual forms on a thin blood smear (detection threshhold: 50 Plasmodium/ $\mu \mathrm{l}$ ). During the study period, all confirmed cases of $P$. vivax received a three-day treatment of chloroquine (total $25 \mathrm{mg} / \mathrm{kg}$ ). Cases with mixed infections and therapeutic treatment failure (attack in the two weeks following the first attack treated correctly) were excluded from the study. In Camopi, treatment with a combination of primaquine (14 days) and chloroquine (3 days) was initiated in 2005, but only for $P$. vivax cases following a first relapse, which did not affect analysis in this study. This prescription of primaquine implies respecting French prescription rules: systematic screening for G6PD deficiency (counter-indication if G6PD deficiency) and delivery as a nominal temporary use authorization.

All parents were given an explanation and written consent was obtained for the study. The study was reviewed and approved by the Ethical Committee of Antilles-Guyane. Two groups of patients were analysed. The first one included the whole population of Camopi children born between January 1, 2001 and December 31, 2008. It was assumed that the first $P$. vivax attack after birth in this group was due to a new infection. The second one included only those who had had a primary attack due to $P$. vivax. In this group, the secondary $P$. vivax attack occurring more than two weeks after a correctly treated primary attack was due to either re-infection or relapse. Therefore, it was assumed that the difference between primary and secondary attack rate of $P$. vivax could be an estimate of the relapse rate. According to the above reasoning, the yearly incidences and the monthly rates of attacks in these groups were estimated using survival analysis methods. Data were right censored by time of child departure from village or death, or time to attack if attack was due to another Plasmodium species. Monthly attack rates were calculated by derivation of the survival curves. Monthly relapse rates were then calculated by difference between the secondary and primary attack rates. All statistical analyses were conducted using R 2.7.1 and the package Epicalc [16]. 


\section{Results}

Between January 2001 and December 2008, 1,042 malaria attacks were recorded in Camopi in 325 children born during this period, of which 319 (31\%) were due to P. falciparum, 689 (66\%) to P. vivax, 21 (2\%) to mixed infections and $13(1 \%)$ to P. malariae or Plasmodium sp. One hundred and fifty one persons had their primary attack with $P$. vivax and 106 had their two first attacks with $P$. vivax. Annual incidence and survival time in the two groups were synthesised in table 1 . Under the working hypothesis 0.12 relapses occurred each year per person who had had a first attack caused by $P$. vivax. Using incidences of each group, the proportion of relapses in the whole secondary $P$. vivax attacks was estimated at $28 \%$.

Figure 1 compares the monthly rate of first $P$. vivax attack since birth and the monthly rate of secondary attack since first $P$. vivax attack classified by the time to attack. The pattern of changes in both groups was clearly distinct. The rate of primary attack seemed to be constant and uniform along the time and was approximately $0.03 \%$ per month and 100 persons at risk. On the contrary, the rate of secondary attacks had a sharp peak during the three first months following the first attack and reached a uniform and constant level after four months comparable to the rate of primary attacks. When relapse rate temporal trends were computed according to the working hypothesis, $P$. vivax relapses were shown to mainly occur during the first three months after the primary attack. A survival curve for relapses was computed. Thirty percent of children never had a relapse, $42 \%$ had a relapse before the first month after the primary attack, 59\% before the second month and $63 \%$ before the third month. After eight months the probability to relapse was nil.

\section{Discussion}

This study showed that, in Camopi, the peak of relapses of $P$. vivax occurred in the first three months after the first attack. After that, most secondary attacks were mainly due to a new $P$. vivax re-infection. These observations confirmed the assumption of a pure tropical pattern with a short latent period for $P$. vivax relapses in French Guiana (Chesson strain [17]). In India, the existence of both tropical and temperate zone types of $P$. vivax characterized by distinct incubation period for relapse were clearly suggested [9].

The current biological methods to differentiate re-infections from relapses have their limits. This study suggests that this simple alternative can estimate the relapse rate in $P$. vivax infection indirectly. However, this method has its own limitations. First, this method to estimate the relapse rate cannot be used in areas where primaquine is associated to chloroquine to treat the first and the second malaria attacks.

Second, it cannot differentiate the relapses from re-infections in individual patients; it estimates the overall relapse rate in the population. It seems that this limitation can be partially resolved by a simple arbitrary classification rule inferred from the results ofthis study. At an individual scale, before 90 days there is a strong probability that the secondary attack is a relapse, after 90 days it is more probable that the secondary attack is a re-infection. By positing that the primary rate of infection is the same than the secondary rate of re-infection, it can be assumed that immunity against $P$. vivax after the primary attack is negligible. As shown elsewhere $[18,19]$, this does not seem to be an unreasonable hypothesis.

Third, similarly, because this study was based on the follow-up of children from birth, the re-infection rate based on the primary attack rate was under-estimated because of the maternal protective immunity during the first 12 months after birth. However, this effect plays in the opposite way of the previous bias and it didn't seem to influence significantly study results.

\section{Conclusion}

This study confirmed that the relapse pattern in Camopi was compatible with the pattern observed with the P. vivax Chesson (tropical) strain. In addition, due to the relapse

Table I: Annual incidence rate ${ }^{\$ *}$ and survival time of the primary and secondary $P$. vivax attack in the Camopi children population.

\begin{tabular}{|c|c|c|c|c|c|c|c|c|}
\hline & \multirow{2}{*}{$\begin{array}{c}\text { STUDIED } \\
\text { POPULATION }\end{array}$} & \multirow{2}{*}{$\begin{array}{l}\text { NUMBER OF } \\
\text { SUBJECTS }\end{array}$} & \multirow{2}{*}{$\begin{array}{l}\text { TIME AT } \\
\text { RISK }\end{array}$} & \multirow{2}{*}{$\begin{array}{l}\text { INCIDENCE } \\
\text { RATE }\end{array}$} & \multicolumn{3}{|c|}{ SURVIVAL TIME (YEAR) } & \multirow{2}{*}{$\begin{array}{l}\text { RELAPSE } \\
\text { INCIDENCE } \\
\text { RATE }\end{array}$} \\
\hline & & & & & $25 \%$ & $50 \%$ & $75 \%$ & \\
\hline $\begin{array}{c}\text { PRIMARY P. } \\
\text { VIVAX } \\
\text { ATTACKS }\end{array}$ & $\begin{array}{l}\text { The Camopi } \\
\text { Children population }\end{array}$ & 325 & 571.76 & 0.31 & 1.23 & 2.33 & 4 & 0 \\
\hline $\begin{array}{c}\text { SECONDARY P. } \\
\text { VIVAX } \\
\text { ATTACKS }\end{array}$ & $\begin{array}{c}\text { Children having had } \\
\text { a primary } P \text {. Vivax } \\
\text { attack }\end{array}$ & 151 & 100.42 & 0.43 & 0.76 & 2.14 & 3.58 & 0.12 \\
\hline
\end{tabular}

\$: Rate unit: attack/persons at risk/per year

*: Right censoring was used in survival analysis 


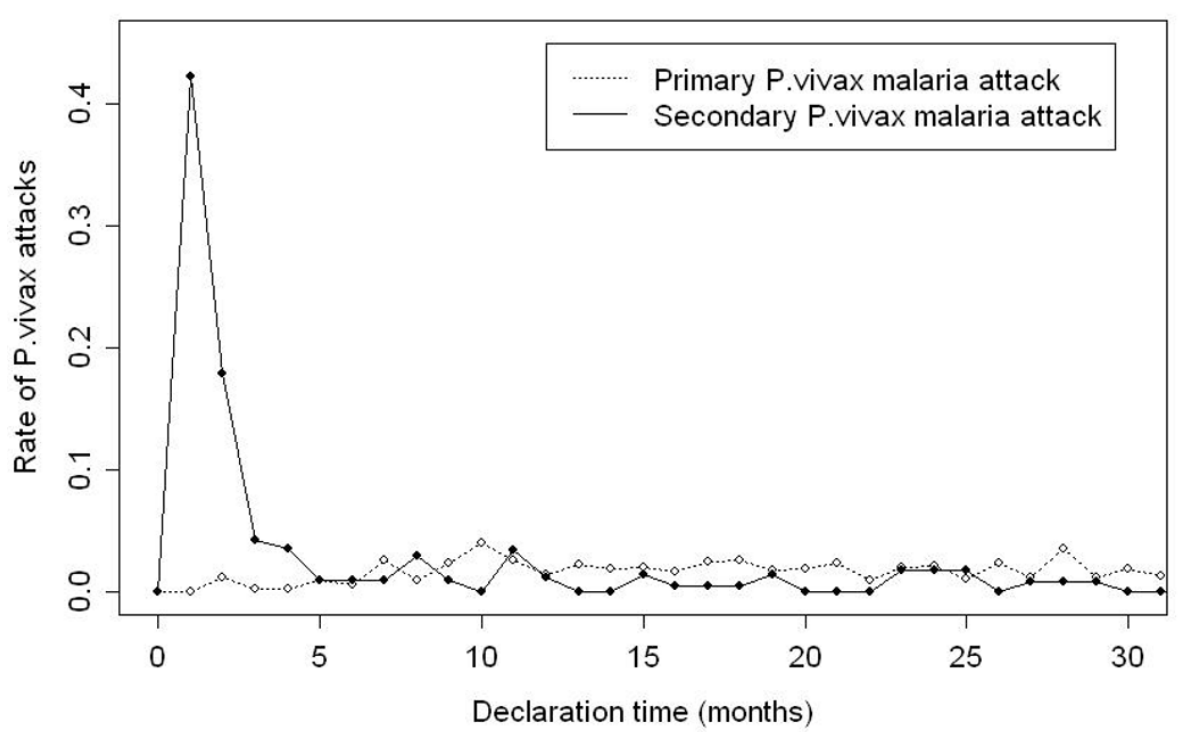

Figure I

Monthly attack rates\$ since birth for the primary $P$. vivax malaria attacks and monthly attack rates $\$$ since the first attack for secondary $P$. vivax attacks. \$ Rate unit: attack/I00 persons at risk/per month.

rate time evolution, a simple arbitrary classification rule could be constructed: before 90 days after the primary attack, the secondary attack is a relapse; after 90 days it is a re-infection. Adapted management of malaria cases based on these results could be devised: systematic prescription of primaquine for all relapses defined by this three-month rule, despite the obligations of screening for G6PD deficiency and administrative formalities involved on French territories. These results could be used in French Guiana and elsewhere in South America to discriminate $P$. vivax relapses from re-infections.

\section{Competing interests}

The authors declare that they have no competing interests.

\section{Authors' contributions}

$\mathrm{MH}$ participated in the research design, performed data analysis and interpretation, and prepared the manuscript. AS was responsible for data collection and participated in manuscript revision. CB participated in data analysis and manuscript revision as well. MN provided guidance on data analyses and was involved in the interpretation of data and manuscript revision. $\mathrm{BC}$ has designed the cohort and initiated the study, and was involved in the interpretation of data and manuscript revision. All authors read and approved the final manuscript

\section{Acknowledgements}

The authors thank the staff of the Health Center of Camopi, particularly Alain Maniglier, Anne Viaud, and Christelle Monnerville for their assistance.
The authors gratefully acknowledge the financial support from EREMIBA project conducted by the UMR 2724 Genetique et Evolution des Maladies Infectieuses (GEMI, IRD) and the Vi-Ve-Pro-Guyane project conducted by Unité de Recherche en biologie parasitaire (URBEP, IMTSSA).

\section{References}

I. Mendis K, Sina BJ, Marchesini P, Carter R: The neglected burden of Plasmodium vivax malaria. Am J Trop Med Hyg 200I, 64:97- 106.

2. Kochar DK, Saxena V, Singh N, Kochar SK, Kumar SV, Das A: Plasmodium vivax malaria. Emerg Infect Dis 2005, II:132-134.

3. Yeom JS, Ryu SH, Oh S, Lee WJ, Kim TS, Kim KH, Kim YA, Ahn SY, Cha JE, Park JW: Status of Plasmodium vivax malaria in the Republic of Korea during 200I-2003. Am J Trop Med Hyg 2005, 73:604-608.

4. Sumawinata IW, Bernadeta, Leksana B, Sutamihardja A, Purnomo, Subianto B, Sekartuti , Fryauff DJ, Baird JK: Very high risk of therapeutic failure with chloroquine for uncomplicated Plasmodium falciparum and $P$. vivax malaria in Indonesian Papua. Am J Trop Med Hyg 2003, 68:416-420.

5. Baird JK: Neglect of Plasmodium vivax malaria. Trends in Parasitology 2007, 23:533-539.

6. Carme B: Substantial increase of malaria in inland areas of eastern French Guiana. Trop Med Int Health 2005, 10:154-159.

7. Abeku TA, van Oortmarssen G], Borsboom G, de Vlas SJ, Habbema JD: Spatial and temporal variations of malaria epidemic risk in Ethiopia: factors involved and implications. Acta Trop 2003, 87:33I-340.

8. Tian L, Bi Y, Ho SC, Liu W, Liang S, Goggins WB, Chan EY, Zhou S, Sung J]: One-year delayed effect of fog on malaria transmission: a time-series analysis in the rain forest area of Mengla County, south-west China. Malar J 2008, 7: II 10.

9. Adak T, Sharma VP, Orlov VS: Studies on the Plasmodium vivax relapse pattern in Delhi, India. Am J Trop Med Hyg 1998, 59:175-179.

10. Prasad RN, Virk KJ, Sharma VP: Relapse/reinfection patterns of Plasmodium vivax infection: a four year study. Southeast Asian J Trop Med Public Health 1991, 22:499-503.

1I. Craig AA, Kain KC: Molecular analysis of strains of Plasmodium vivax from paired primary and relapse infections. J Infect Dis 1996, 174:373-379. 
12. Kirchgatter K, del Portillo HA: Molecular analysis of Plasmodium vivax relapses using the MSPI molecule as a genetic marker. $J$ Infect Dis 1998, 177:5I I-5 I5.

13. Veron V, Legrand E, Yrinesi J, Volney B, Simon S, Carme B: Genetic diversity of msp3alpha and mspl_b5 markers of Plasmodium vivax in French Guiana. Malar J 2009, 8:40.

14. Carme B, Lecat J, Lefebvre P: Le Paludisme en Guyane dans le foyer de l'Oyapock. Incidence des accès palustres chez les amérindiens de Camopi. Med Trop (Marseille) 2005, 65: I49-I54.

15. Hustache S, Nacher M, Djossou F, Carme B: Malaria risk factors in amerindians children in French Guiana. Am J Trop Med Hyg 2007, 76:619-625.

16. Chongsuvivatwong $\mathrm{V}$ : Analysis of epidemiological data using $\mathbf{R}$ and Epicalc. Edited by: McNeil. Special Programme for Research \& Training in Tropical Diseases (TDR); 2007.

17. Ehrman FC, Ellis JM, Young MD: Plasmodium vivax Chesson strain. Science 1945, 101:377.

18. Molineaux L, Storey J, Cohen JE, Thomas A: A longitudinal study of human malaria in the West African Savanna in the absence of control measures: relationships between different Plasmodium species, in particular $P$. falciparum and $P$. malariae. Am J Trop Med Hyg 1980, 29:725-737.

19. Mason J: Patterns of Plasmodium vivax recurrence in a highincidence coastal area of El Salvador, C. A. Am J Trop Med Hyg 1975, 24:58|-585.

Publish with Bio Med Central and every scientist can read your work free of charge

"BioMed Central will be the most significant development for disseminating the results of biomedical research in our lifetime. "

Sir Paul Nurse, Cancer Research UK

Your research papers will be:

- available free of charge to the entire biomedical community

- peer reviewed and published immediately upon acceptance

- cited in PubMed and archived on PubMed Central

- yours - you keep the copyright

Submit your manuscript here:

http://www.biomedcentral.com/info/publishing_adv.asp
BiolMedcentral 